\title{
Solar activity effects in the ionospheric D region*
}

\author{
A. D. Danilov \\ Institute of Applied Geophysics, Rostokinskaya 9, Moscow 128 129, Russia Fax: + 709518775 13; e-mail: geophys@sovam.com \\ Received: 5 November 1997 / Revised: 13 February 1998 / Accepted: 18 February 1998
}

\begin{abstract}
Variations in the D-region electron concentration within the solar activity cycle are considered. It is demonstrated that conclusions of various authors, who have analyzed various sets of experimental data on [e], differ significantly. The most reliable seem to be the conclusions based on analysis of the [e] measurements carried out by the Faraday rotation method and on the theoretical concepts on the D-region photochemistry. Possible QBO effects in the relation of [e] to solar activity are considered and an assumption is made that such effects may be the reason for the aforementioned disagreement in conclusions on the [e] relation to solar indices.
\end{abstract}

Key words. Atmospheric composition and structure · Ion chemistry of the atmosphere $\cdot$ Middle atmosphere

\section{Introduction}

The study of the lowest part of the ionosphere (the D region at altitudes of $50-90 \mathrm{~km}$ ) still meets problems, even though some of the problems have been understood since the sixties (e.g Danilov, 1970).

One of the problems is the D-region electron concentration dependence on the solar activity level. In spite of the fact that during the recent decades the problem has been considered in many publications based on various data (see in the following Table 1 and Sect. 2), still there is no commonly accepted opinion on the character of [e] variations from maximum to minimum of a solar cycle [that is under variations of

*Paper Presented at the Second IAGA/ICMA (IAMAS) Workshop on Solar Activity Forcing of the Middle Atmosphere, Prague, August 1997 the most used indices $\mathrm{F}(10.7)$ (solar radio emission flux at $10.7 \mathrm{~cm}$ ) and $R$ (sunspot number)].

The difference of opinion on the aforementioned dependency is very strong. For example, in the lower part of the $\mathrm{D}$ region (a characteristic height of $60 \mathrm{~km}$ ), some authors obtain an increase in [e] with solar activity, while others obtain a decrease. In the upper part of the D region (a characteristic height of $80 \mathrm{~km}$ ) conclusions of various authors vary from a complete absence of the dependence to an [e] increase by 3.5 times. Conclusions of various investigators are so conflicting that even within the IRI Working Group there is no unanimous opinion on the dependence of [e] on $F(10.7)$ and $\mathrm{R}$, though the vast majority of the specialists believe that the dependency presented in the current version IRI-90 should be dealt with more explicity.

Danilov (1989) considered the problem of solar activity impact on the $\mathrm{D}$ region from a general point of view. It was shown that from physical considerations one can expect a weak increase in [e] with solar activity in the upper part of the $\mathrm{D}$ region, which is, however, difficult to detect.

During the recent decade several groups of publications dedicated to the problem in question have appeared. The aim of this paper is to consider the conclusions of various authors on the D-region electron concentration dependence on solar activity in quiet background conditions and suggest a possible explanation of the difference in results obtained. Only quiet conditions at middle latitudes are considered. The Dregion reaction to solar events and related energetic particle precipitations and geomagnetic disturbances presents a separate problem (see e.g. Lastovicka 1988, 1996).

\section{Dependence of [e] on solar activity according to various authors}

For the sake of convenience of analysis and discussion, we split all the papers considered into several categories 
Table 1. Estimates of $[\mathrm{e}]$ variations in the $\mathrm{D}$ region from high to low solar activity $(r=[\mathrm{e}](h) /[\mathrm{e}](l))$

\begin{tabular}{|c|c|c|c|c|c|c|}
\hline author & \multicolumn{4}{|c|}{ height, km } & interval of $\mathrm{F}(10.7)$ & interval of $R$ \\
\hline \multicolumn{7}{|l|}{ 1. Rockets (homogeneous sets) } \\
\hline Mechtly et al. (1972) & & 2 & 3.6 & 1.6 & & \\
\hline Knyazev et al. (1994) & 1.0 & 1.2 & 1.4 & 1.5 & & $10-100$ \\
\hline \multicolumn{7}{|c|}{ 2. Empirical models based on rocket data } \\
\hline Danilov et al. (1995) & 1.0 & 1.0 & 1.0 & 2.0 & $70-200$ & \\
\hline Friedrich and Torkar (1997) & 0.3 & 1.4 & 1.5 & 1.6 & $67-130$ & \\
\hline \multicolumn{7}{|c|}{ 3. Empirical models based on mixed data } \\
\hline IRI-90 & & 1.9 & 2.0 & 2.0 & & $10-100$ \\
\hline McNamara (1979) & 1.6 & 1.0 & 1.6 & 1.0 & & $0-100$ \\
\hline \multicolumn{7}{|l|}{ 6. Theoretical models } \\
\hline Smirnova et al. $(1984,1988)$ & 0.9 & 0.9 & 1.1 & 1.5 & $75-150$ & \\
\hline
\end{tabular}

(see Table 1) according to the experimental material used to derive the dependencies obtained.

It is widely known that the problem of D-region electron concentration measurements meets serious technical difficulties. This may be a reason for some contradictions in views on both absolute [e] values and the character of their variations. In this situation, it is of interest to compare [e] measurements on board rockets with the same instrument. Even if the method has a systematic error in measurements of the absolute [e] values, it may provide correct relative variations (from one solar zenith angle to another, from one solar activity level to another, etc.), if the error is kept constant from one flight to another.

To compare results of various authors we will here consider the ratio $r=[\mathrm{e}](\mathrm{h}) /[\mathrm{e}](\mathrm{I})$ of the electron concentration under high and low solar activity, indicating, where possible, to which interval of $\mathrm{F}(10.7)$ or $R$ the ratio refers (see Table 1).

Mechtly et al. (1972) compared the probe measurements (calibrated to onboard Faraday data) of five rocket flights in April-December 1965 (low solar activity) with five flights in July-December 1969 (high solar activity). The measurements were conducted at Wallops Island $\left(38^{\circ} \mathrm{N}\right)$ under solar zenith angles of about $60^{\circ}$. Mechtly et al. (1972) concluded that at all altitudes considered $(70-90 \mathrm{~km})$ [e] increased with solar activity and obtained the highest (out of evaluations of all the authors) amplitude of the [e] increase at $80 \mathrm{~km}: r=3.6$. An even higher value $(r=8)$ was reported by Mechtly et al. (1972) at $85 \mathrm{~km}$; however, the existence of such a sharp maximum between 80 and $90 \mathrm{~km}$ seems doubtful.

On the basis of 14 rocket probe measurement of [e] at Thumba $\left(8^{\circ} \mathrm{N}\right)$ in $1979-1980[\mathrm{~F}(10.7)$ varied from 139 to 243], Pakhomov (1983) obtained a positive correlation between [e] at $75 \mathrm{~km}$ and $\mathrm{F}(10.7)$ with the correlation coefficient of 0.77 . In the later publication of the same authors (Knyazev et al.,1994), the D-region electron concentration dependence on solar activity was studied on the basis of 80 rocket measurements in Thumba by a probe method. The rockets were flown under solar zenith angles of $\chi=71 \pm 2$ in 1979-1990 and 19841987.

This set of data made it possible to conclude that the sign of the solar activity effect changes with altitude: [e] decreases with $\mathrm{F}(10.7)$ increase $(r<1)$ in the lowest $\mathrm{D}$ region and increases in the upper $\mathrm{D}$ region $(r>1)$, the $r=1$ boundary being located near $60 \mathrm{~km}$. However Knyazev et al. (1994) obtained much lower amplitude of the effect at $80 \mathrm{~km}(r=1.35)$ than Mechtly et al. (1972).

The rocket probe measurements of the foregoing group at several sites (Thumba, Volgograd, Heiss Island) have been generalized in an empirical model (Knyazev et al.,1993; Singer et al.,1994). According to this model, the amplitude of [e] dependence on solar activity varies with the solar zenith angle, decreasing toward high values of $\chi$. Table 1 shows the values of $r$ according to this model at middle latitudes (Volgograd, $\left.\varphi=48.7^{\circ}\right)$ and $\chi=60^{\circ}$.

Rocket measurements of [e] conducted by various authors have been used in the Chasovitin (1983) model. At all the D-region heights above $65 \mathrm{~km}$ the [e] dependence in the form:

$[\mathrm{e}] \sim(0.46+0.0067 \mathrm{R})$

which gives $r=2.1$ under transition from $R=10$ to $R=100$, was accepted.

Only the most reliable rocket measurements of the electron concentration by the Faraday rotation method were used in the Danilov et al. (1995) empirical model. 
No [e] dependence on solar activity within the scatter of the experimental data available was found at most altitudes of the $\mathrm{D}$ region $(h<85 \mathrm{~km})$. The indicated scatter depends very much on the season and is much stronger in winter than in summer. In the summer period, taking into account the aforementioned scatter, one can state that the solar activity effect (if any) does not exceed the factor of 1.4.

At $90 \mathrm{~km}$ Danilov et al. (1995) obtained a wellpronounced increase in [e] with solar activity. It was also found that $r$ depends on the solar zenith angle, decreasing from 2.8 at $\chi=45^{\circ}$ to 1.4 at $\chi=85^{\circ}$. Both the fact of the relation between [e] and $\mathrm{F}(10.7)$ and the decrease in $r$ with $\chi$ agree well with theoretical concepts (see Sect. 4).

A similar approach to the choice of experimental data on [e] in creation of the D-region model was used by Friedrich and Torkar (1992, 1997). Only rocket measurements by the Faraday rotation method (many of which have been conducted by these authors themselves) were used and an empirical model of the Dregion electron concentration was created. According to this model, the solar activity effect also depends on the solar zenith angle. Table 1 shows the values of $r$ for $\chi=60^{\circ}$.

The McNamara (1979) and IRI-90 (Bilitza, 1990) models should be referred to the models based on a combination of various data (both rocket and ground based). McNamara (1979) obtained unusual [e] dependence on solar activity: an increase in [e] by 1.6 times (under increase in $R$ from 0 to 100 ) at 60 and $80 \mathrm{~km}$ and almost complete absence of the effect $(r=1)$ at 70 and $90 \mathrm{~km}$. Such vertical profile of $\mathrm{r}$ seems unrealistic and should, apparently, be explained by the fact that very heterogeneous data (some of which are unreliable in determination of absolute [e] values) were used to create the model.

In the most commonly used empirical model IRI, [e] increases with solar activity at all the D-region heights. The amplitude of the effect seems to be overestimated in the upper part of the $\mathrm{D}$ region (see the following).

Though ground-based measurements of [e] in the D region have been criticized because of some principal difficulties in obtaining electron concentration absolute values in these measurements, it is worth comparing the conclusions on the effect in question based on these measurements. A large data set of [e] measurements by the partial reflection method was compiled by Belikovich et al. (1992). The model built on this data base yields $r=2.6$ at $70 \mathrm{~km}$ and 1.4 at $80 \mathrm{~km}$ when $\mathrm{F}(10.7)$ changes from 70 to 200 .

Sengupta (1980) presented measurements of [e] in the $D$ region $(68-82 \mathrm{~km})$ by the incoherent-scatter method in Arecibo $\left(19^{\circ} \mathrm{N}\right)$ in two sessions under moderate $(15$ September 1977) and low (20 April 1975) solar activity. According to these measurements, $r=1.1$ and 1.5 at 70 and $80 \mathrm{~km}$, respectively.

It is widely known that some monitoring of the D region is provided by radio-wave propagation methods (measurements of the absorption $L$ by the A1 and A3 methods, detection of the reflection heights $h_{p}$, and others). The variations of $L$ and $h_{p}$ (including solar activity effects) have been analyzed in many publications. Their consideration is outside the scope of this paper. To compare with the [e] measurements just described we present here only the data of the classic paper by Lauter (1977) and a review by Bremer and Singer (1977), who summarized the results of radiowave propagation studies in a broad range (10-2500 $\mathrm{kHz}$ ) and derived conclusions on [e] variations at various heights of the $\mathrm{D}$ region.

According to Lauter (1977) the changes in radiowave absorption when switching from maximum to minimum of the solar activity depend on both the radio frequency and season. However, the value of $L(\max ) / L(\min )$ is very small and lies mainly within the 1.05-1.20 range. Only in one case (March, equivalent frequency of $170 \mathrm{kHz}$ ) does this value exceed 1.20 . If we assume that $L$ is roughly proportional to [e], we may consider the $L(\max ) / L(\min )$ values as some indicator of $r$ variations.

According to Bremer and Singer (1977) the solar activity effect is also small and positive $[r>1$ for the transition from $\mathrm{F}(10.7)=75$ to $\mathrm{F}(10.7)=150$ ] at all the altitudes of the $\mathrm{D}$ region (see Table 2). Also, the tendency already mentioned of an effect weakening with an increase in the solar zenith angle is seen.

Summarizing the conclusions based on various experimental data, one has first of all to emphasize a strong scatter of the results well seen in Table 1. The amplitudes of the [e] increase in the upper part of the D region differ. The conclusions even on the sign of the solar activity effect in the lower part of the $\mathrm{D}$ region are opposite. No such strong discrepancy is observed for [e] dependence on other parameters (for example, $\chi$ or the season). The latter fact makes it impossible to explain the contradictions in the results on the [e] dependence on $\mathrm{F}(10.7)$ and $R$ only by low reliability of the initial experimental data. Probably the reason for the contradictions is more complicated and of principal nature.

\section{The D Region and quasi-biennial oscillations}

Publications by Labitzke (1987), Labitzke and van Loon (1988) and Labitzke and Chanin (1988) made it possible to look from a new angle at the very problem of the search for thermobaric parameter variations in the lower and middle atmosphere with solar activity. It was found

Table 2. Values of $r$ according to Bremer and Singer (1977) (summer, $50^{\circ} \mathrm{N}$ )

\begin{tabular}{lllll}
\hline & 40 & 60 & 70 & 80 \\
\hline 60 & & & & \\
65 & 1.26 & 1.36 & 1.18 & 1.05 \\
70 & 1.34 & 1.25 & 1.34 & 1.16 \\
75 & 1.27 & 1.46 & 1.34 & 1.35 \\
80 & 1.10 & 1.13 & 1.40 & 1.46 \\
85 & 1.10 & 1.14 & 1.36 & 1.30 \\
90 & 1.13 & 1.54 & 1.41 & 1.15 \\
\hline
\end{tabular}


that the effects of $T$ and $p$ variations significantly depend on the phase of the quasi-biennial oscillations (QBO) of the wind zonal component in the stratosphere over the equator. Therein, during the western and eastern phases of the QBO, opposite relation of $T$ and $P$ to $\mathrm{F}(10.7)$ and $R$ may be observed, whereas under the analysis of all the data together (without splitting according to the QBO phase) no meaningful correlation with solar activity may be observed (Labitzke, 1987; Labitzke and Chanin, 1988; Labitzke and van Loon, 1988). If so, it is worth looking at a different angle also at variations of [e] in the $\mathrm{D}$ region with the solar activity.

Danilov et al. (1992) analyzed the mean January values of $L$ at the Pristina-Sofia circuit $(1412 \mathrm{kHz}, 170$ $\mathrm{km}$ ) during 1970-1990. It was found that if all the data for the entire period are analyzed, only a slight tendency of $L$ increase with solar activity is revealed. Separation of the whole set of data for years of the western and eastern phases of the QBO did not lead to significantly new conclusions due to a decrease in statistics (Fig. 1).

Danilov et al. (1992) proposed to seek a dependence on solar activity of not the $L$ value itself but the number of days $n$ (say, during the winter period), when this absorption exceeds by some threshold value $(8 \mathrm{~dB})$ the mean absorption during the period considered. The variations of $n$ versus the $R$ index for all the years are shown in Fig. 2. One can see that $n$ decreases as $R$ increases the dependency being better pronounced for the western phase years (the correlation coefficient $k=0.8,>99 \%$ significance).

This result means that the number of days with excessive absorption (days of the winter anomaly WA) in the $\mathrm{D}$ region decreases with an increase in the solar activity. This conclusion is important for solving the problem of the WA event mechanisms, outside the scope of this paper.

We have analyzed the noon values of $L$ measured by the A3 method at $129 \mathrm{kHz}$ (the Zeven-Kuhlungsborn circuit, $188 \mathrm{~km}$ ) and $245 \mathrm{kHz}$ (Kalundborg-Kuhlungs-

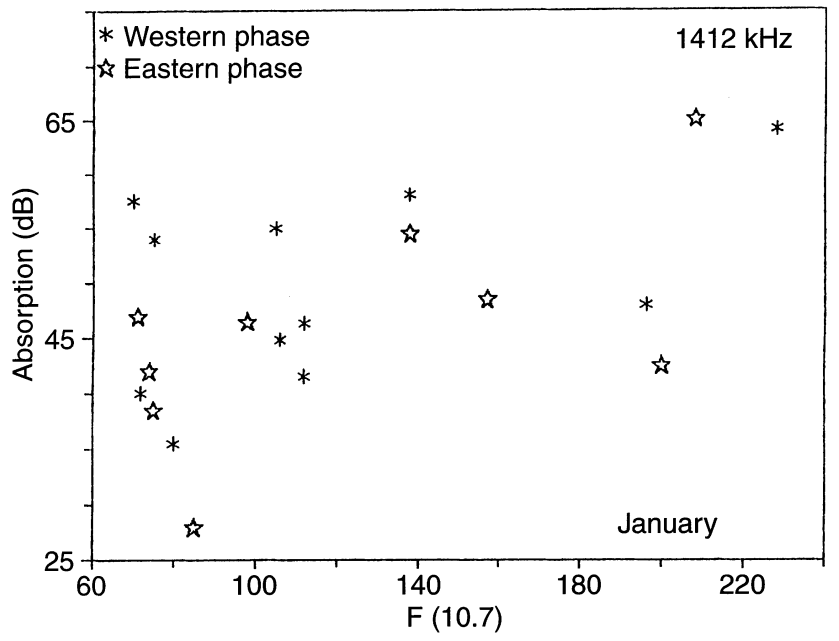

Fig. 1. Dependency of the absorption $L$ at $1412 \mathrm{kHz}$ (January 19701990) on the $F(10.7)$ index according to Danilov et al. (1992) under different QBO phases

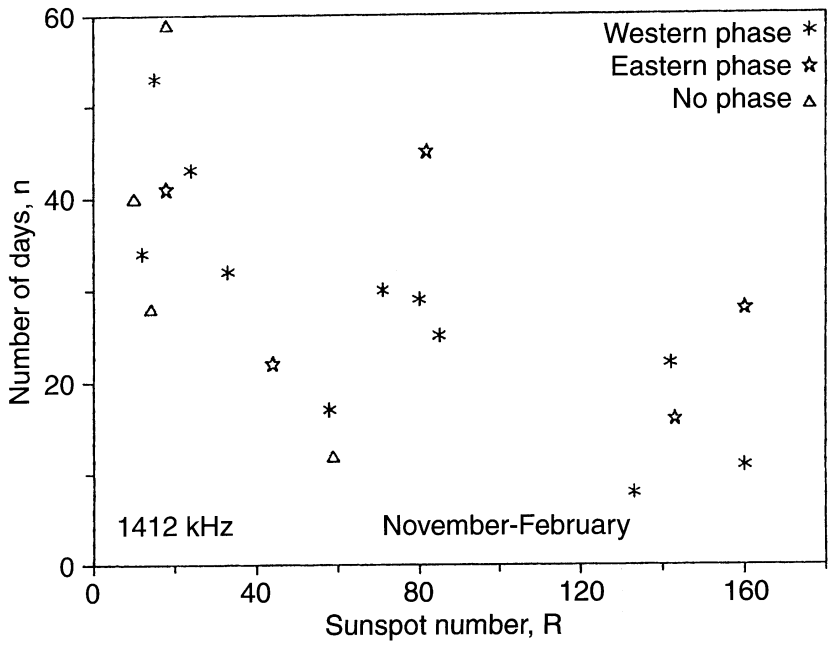

Fig. 2. Dependency of the number of days $n$ with the excessive absorption $\Delta L=8 \mathrm{~dB}$ on $R(1412 \mathrm{kHz}$, winter months, 1970-1990) according to Danilov et al. (1992) under different QBO phases ("no phase" means that there was a phase reversal in the middle of the particular winter)

Table 3. Correlation between $L$ and solar activity indices; correlation coefficients for quiet days $(\mathrm{Ap}<20)$ are shown in parenthesis

\begin{tabular}{lllll}
\hline frequency, & index & \multicolumn{2}{l}{ correlation coefficients } \\
\cline { 3 - 5 } & & $\begin{array}{l}\text { whole } \\
\text { set }\end{array}$ & $\begin{array}{l}\text { western } \\
\text { phase }\end{array}$ & $\begin{array}{l}\text { eastern } \\
\text { phase }\end{array}$ \\
$\mathrm{kHz}$ & $R$ & $0.2(0.3)$ & $0.4(0.4)$ & $0.1(0.1)$ \\
245 & $R$ & $0.4(0.3)$ & $0.5(0.5)$ & $0.2(0.2)$ \\
129 & $\mathrm{~F} \mathrm{(10.7)}$ & $0.3(0.3)$ & $0.5(0.4)$ & $0.2(0.2)$ \\
245 & $\mathrm{~F}(10.7)$ & $0.4(0.4)$ & $0.5(0.5)$ & $0.2(0.3)$ \\
129 & & & & \\
\hline
\end{tabular}

born, $178 \mathrm{~km}$ ) during 1960-1982. To exclude the seasonal variations of the absorption, the values of $L$ averaged over January-February were used and compared with the corresponding values of $\mathrm{F}(10.7)$ and $R$. The correlation coefficients $k$ between $L$ and the solar indices are shown in Table 3.

Table 3 demonstrates that the value of $k$ for the western years of the QBO is systematically higher than for the whole set of data and for the eastern years. Actually, no correlation is observed in the years of the eastern phase and that determines the low values of $k$ obtained in the analysis of all the years together.

In order to eliminate possible effects of the magnetic activity, the mean values of $L$ for the same periods were calculated only for days with the magnetic index Ap below 20. The correlation coefficients obtained in such a way are presented in Table 3 in parentheses. One can see that the exclusion of magnetically disturbed days hardly influences the correlation coefficients obtained.

Figure 3 shows the $L$ values for the western years of the QBO versus $R$. One can see that some sort of a "saturation" effect under high $R$ is observed. To carry out a more detailed study of the effect, the correlation between $L$ and $R$ (separately for the western and eastern 


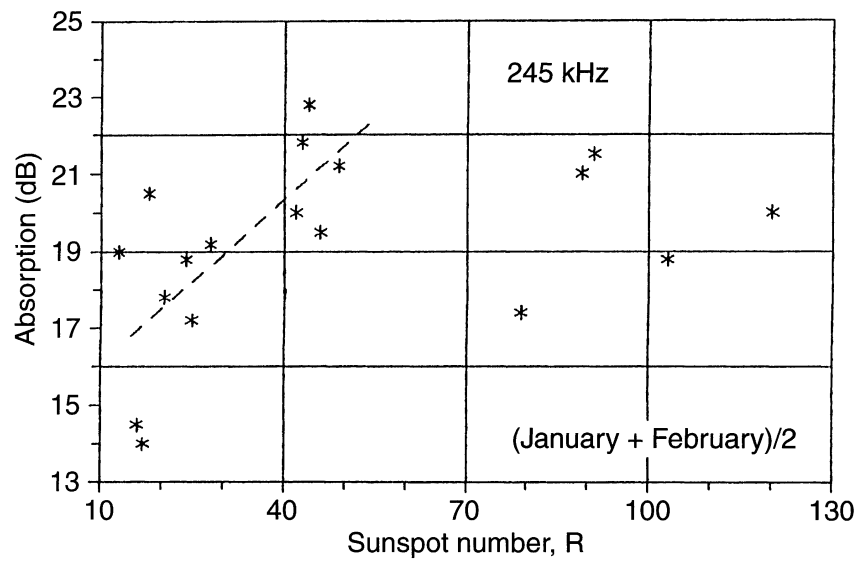

Fig. 3. Dependency of the absorption at $245 \mathrm{kHz}$ averaged over January-February on $R$ for the QBO western phase (1960-1982)

phases of the QBO) was calculated for the entire data set and for the months when $R$ did not exceed 120,80 and 60. The results are shown in Table 4 .

Table 4 demonstrates that a saturation effect really exists and screens both the relation between $L$ and $R$ and the QBO effects. The most pronounced positive correlation between $L$ and $R(k=0.7)$ is observed for the years of the QBO western phase and a frequency of 245 $\mathrm{kHz}$ at $R<60$. Under these conditions negative correlation is observed in the eastern phase years, and that accounts for the low values of $k$ obtained under consideration of all the years together.

The dependency of the effect on frequency is also seen. The negative correlation between $L$ and $R$ is most pronounced for the eastern years and the $129 \mathrm{kHz}$ frequency for $R<60$, whereas under these conditions the effect at $245 \mathrm{kHz}$ is small. This difference is evidently due to different dependence on the solar activity of various parts of the $\mathrm{D}$ region, which reflects radio waves of the indicated frequencies.

The foregoing conclusions on dependence of the relation between $L$ and $R$ on the QBO phase make it possible to look from a new angle at the problem of [e] relation to the solar activity formulated in Sect. 2. It is quite probable that the difference in opinion on [e] and $L$ dependency on $R$ and $\mathrm{F}(10.7)$ discussed already in detail is due to the very fact that in all the comparisons of these parameters all the data available have been analyzed without any separation to the years of different QBO phases.

\section{Theoretical concepts of the [e] relation to solar activity}

A complete scheme of the ionization-recombination transformations in the $\mathrm{D}$ region is rather complicated and includes many processes whose efficiency is not always reliably known. Nonetheless, D-region theoretical models, which describe the principal links of the foregoing schemes with various degree of reliability, have been created. Here we consider briefly the possible relation of [e] to the solar activity on the basis of the theoretical D-region model by Smirnova et al. (1984, 1988)

The most obvious source of the preceding relation is variations with solar activity of the intensity of the radiation, which produces ionization (that is, governs the values of the ionization rate $q$ ). It is known that several sources are responsible for the D-region ionization: the solar Layman-alpha line, which ionizes NO molecules, solar radiation in the $\lambda=111.8-102.7-\mathrm{nm}$ interval, which ionizes the excited $\mathrm{O}_{2}\left({ }^{1} \Delta_{g}\right)$ molecules, solar X-rays below $3 \mathrm{~nm}$, and galactic cosmic rays (the two latter sources ionize all neutral molecules).

The variations of each of these radiations with the solar activity present a special problem, which is outside the scope of this paper. We present here the most reliable (in our opinion) values of these variations used by Smirnova et al. $(1984,1988)$ to evaluate the effects expected in the $\mathrm{D}$ region.

Table 5. Values of $r$ according to the theoretical model by Smirnova et al. $(1984,1988)$ (summer, $50^{\circ} \mathrm{N}$ )

\begin{tabular}{lll}
\hline$h, \mathrm{~km}$ & $\chi=66^{\circ}$ & $\chi=78.5^{\circ}$ \\
\hline 60 & 0.80 & 0.76 \\
65 & 0.85 & 0.81 \\
70 & 1.06 & 0.90 \\
75 & 1.24 & 1.03 \\
80 & 1.31 & 1.15 \\
85 & 1.54 & 1.27 \\
90 & 1.88 & 1.53 \\
\hline
\end{tabular}

Table 4. Correlation between $L$ and $R$ under various limitations on $R$

\begin{tabular}{|c|c|c|c|c|c|c|c|}
\hline \multirow{2}{*}{$\begin{array}{l}\text { values of } \\
R \text { smaller than }\end{array}$} & \multicolumn{3}{|c|}{ number of points } & \multirow{2}{*}{$\begin{array}{l}\text { frequency } \\
\mathrm{KHz}\end{array}$} & \multicolumn{3}{|c|}{ correlation coefficient } \\
\hline & whole set & $\mathrm{E}$ & W & & whole set & $\mathrm{E}$ & $\mathrm{W}$ \\
\hline \multirow[t]{2}{*}{60} & \multirow[t]{2}{*}{23} & \multirow[t]{2}{*}{10} & \multirow[t]{2}{*}{3} & 245 & 0.3 & -0.1 & 0.7 \\
\hline & & & & 129 & 0.0 & -0.5 & 0.3 \\
\hline 120 & 34 & 17 & 17 & 129 & 0.3 & 0.1 & 0.5 \\
\hline \multirow[t]{2}{*}{ whole set } & \multirow[t]{2}{*}{38} & \multirow[t]{2}{*}{20} & \multirow[t]{2}{*}{18} & 245 & 0.2 & 0.1 & 0.4 \\
\hline & & & & 129 & 0.4 & 0.2 & 0.5 \\
\hline
\end{tabular}


The Lyman-alpha intensity grows from minimum to maximum of the solar activity by 1.7 times. The intensity of the radiation within the $111.8-102.7-\mathrm{nm}$ interval increases by a factor of 2 . The intensity of the X-rays in the $1.2-100-\mathrm{nm}$ interval (this very interval is the main contributor to the ionization at altitudes of the D-region upper part) increases by 7 times. The cosmic ray intensity decreases at middle latitudes by about a factor of 2 .

Variations of the minor constituents $\left(\mathrm{NO}, \mathrm{O}_{3}, \mathrm{H}_{2} \mathrm{O}\right.$, etc.) may be one of the sources of [e] variability during a solar cycle. According to current ideas, NO, the principal ionized constituent in the upper part of the D region, shows no significant variations with $F(10.7)$. As for the minor constituents, which play important roles in the lower D region, still only little is known regarding their variations, thus, as a first approximation, they were taken independently of solar activity in evaluating the $r$ values (Smirnova et al., 1984, 1988).

The [e] variations at various heights in summer at the $50^{\circ} \mathrm{N}$ latitude according to the Smirnova et al. (1984, 1988) model are shown in Table 5. One can see from this table that the theory really predicts a decrease in [e] with solar activity in the lower part of the $\mathrm{D}$ region and an increase in the upper part. The effect of an $r$ decrease with a $\chi$ increase (detected in the experimental data, see Sect. 2 ) is well seen and is due to the increase under high $\chi$ of the absorption of, first of all, solar X-rays, which are the main contributor to $r$. The value of $r=1.3$ at $80 \mathrm{~km}$ does not contradict the estimate by Danilov et al. (1995) and is only slightly less than the $r$ value given by Friedrich and Torkar (1997). It should be emphasized that these papers are based on the analysis of the most reliable rocket measurements of [e] by the Faraday rotation method.

As for theoretical interpretation of dependence of the character of the [e] relation to the solar activity on the QBO phases, a principal possibility (and even inevitability) of such a relation follows from the results by Labitzke and Chanin (1988). It is evident from Fig. 1 of that paper that a complicated vertical profile of the correlation coefficient $k$ between $T$ and $R$ is observed at the D-region heights, the profile being different for different QBO phases. At least as far as the upper part of the $\mathrm{D}$ region is concerned, the [e] value depends strongly on the temperature (Smirnova et al., 1984, 1988), one should expect a relation between [e] and $R$, which would also depend on the QBO phase.

Unfortunately, one should not expect a well-pronounced reaction of $L$ to the QBO phase. The heights, which determine the radio-wave absorption at the frequencies considered, vary depending on several external factors (the circuit length, the solar zenith angle, etc.) and on the whole are located within the 77-83-km interval. It follows from the aforementioned figure by Labitzke and Chanin (1988) that in this very height interval the character of the dependence of $T$ on $R$ changes very sharply with altitude, so even a small change in the radio-wave absorption altitude would lead to drastic changes in the character of the relation between [e] (and thus $L$ ) with $R$. Therein, both similar variation of $L$ with $R$ under western and eastern phases (both correlation coefficients at $80 \mathrm{~km}$ are positive) is possible as well as opposite variations (the signs of $k$ are different below 80 $\mathrm{km})$. Both types of variations are observed in the experimental data on $L$ considered in Sect. 3 .

\section{Conclusions}

Various authors obtain different amplitudes of the Dregion electron concentration variation from minimum to maximum of the solar activity. Currently the evaluations based on the analysis of the rocket measurements by the Faraday rotation method (Danilov et al., 1992; Friedrich and Torkar, 1997) seem to be the most reliable. These evaluations in the upper part of the $\mathrm{D}$ region agree with the theoretical evaluations by Smirnova et al. $(1984,1988)$.

The inverse relation between [e] in the $\mathrm{D}$ region and the solar indices, which follows from the analysis of the electron concentration rocket measurements and the theoretical model by Smirnova et al. $(1984,1988)$, seems to be real.

An attempt is made to consider the D-region behavior within the solar cycle on the basis of the data on $L$ with allowance for the quasi-biennial oscillations. The results show that a direct relation between $L$ and $R$ is observed under the western phase of the QBO and there exists a saturation effect at $R>60$. For $R<60$ the correlation coefficient is high enough $(k=0.7)$. This fact may explain the discrepancy of conclusions of different authors regarding the [e] dependence on $R$ and $\mathrm{F}(10.7)$, because the measurements for all years have been considered together.

Acknowledgements. The author thanks Dr. N. V. Smirnova for her help in preparing the paper.

Topical Editor F. Vial thanks M. Friedrich and G. Entzian for their help in evaluating this paper.

\section{References}

Belikovich, V. V., E. A. Benediktov, E. A. Vyakhirev, and A. M. Lerner, The empirical model of the electron concentration distribution in the midlatitude D region (in Russian), Geomagn Aeron., 32, 339, 1992.

Bilitza, D., International reference ionosphere 1990, NSSDC, WDC-A-R \& 90-22, 1990.

Bremer, J., and W. Singer, Diurnal, seasonal, and solar-cycle variations of electron densities in the ionospheric D and E regions, J. Atmos. Terr. Phys., 39, 25, 1977.

Chasovitin, Yu. K., The reference model of distribution of the electron concentration, temperature, and collision frequency in the ionosphere below $200 \mathrm{~km}$, VNIIGMI-MTsD, Obninsk, 1983.

Danilov, A. D., Chemistry of the ionosphere, Plenum Press, New York, 1970.

Danilov, A. D., General overview of the solar activity effects in the lower ionosphere, Aeron. Rep., 29, 183, 1989.

Danilov, A. D., G. Nestorov, and D. Pancheva, Ionospheric Dregion and solar activity (in Russian), Geomagn. Aeron, 32, 107, 1992.

Danilov, A. D., A. Yu. Rodevich, and N. V. Smirnova, Problems with incorporating a new D-region model into the IRI, $A d v$. Space Res., 15, 165, 1995. 
Friedrich, M., and K. M. Torkar, An empirical model of the nonauroral D region, Radio Sci., 27, 945, 1992.

Friedrich, M., and K. M. Torkar, Empirical D-region modeling, a progress report, Paper presented at the -PRIME/IRI Workshop, Kuhlungsborn, Germany, 27-31, May, 1997.

Knyazev, A. K., L. V. Korneeva, V. N. Avdeev, and L. B. Vanina, Specification of the empirical model of the D-region electron concentration relation to the zenith angle according to rocket measurements, Geomagn. Aeron (in Russian), 33, 163, 1993.

Knyazev, A. K., L. B. Vanina, L. V. Korneeva, and V. N. Avdeev, The N-profiles of the equatorial lower ionosphere, Geomagn. Aeronomy (in Russian), 34, 152, 1994.

Labitzke, K, Sunspots, the QBO, and the stratospheric temperatures in the polar region, Geophys. Res. Lett.,4,535, 1987.

Labitzke, K, and M-L. Chain, Changes in the middle atmosphere in winter related to the 11-year solar cycle, Ann. Geophys., 6, 643, 1988.

Labitzke, K., and H. van Loon, Associations between the 11-year solar cycle, the QBO, and the atmosphere. Part 1: The troposphere and stratosphere in the northern hemisphere in winter, J. Atmos. Terr. Phys.,50, 197, 1988.

Lastovicka, J., A review of solar wind and high energy particle influence on the middle atmosphere, Ann. Geophys., 6, 401, 1988.
Lastovicka, J., Effects of geomagnetic storms in the lower ionosphere, middle atmosphere and troposphere, J. Atm. Terr. Phys., 58, 831, 1996.

Lauter, E. A., D-region winter anomaly and solar cycle, Phys. Solariterr. Potsdam, 6, 67, 1977.

McNamara, L. F., Statistical model of the D-region, Radio Sci., 1, $1165,1979$.

Mechtly, E. A., S. A. Bowhill, and L. G. Smith, Changes of lower ionosphere electron concentration with solar activity, J. Atmos. Terr. Phys., 34, 1899, 1972.

Pakhomov, S. V., and A. N. Gorbunov, The n(h)-profiles in the Dregion of the equatorial zone (in Russian), Geomagn. Aeron., 23, 134, 1983.

Sengupta, P. R., Solar x-ray control of the D region of the ionosphere, J. Atmos. Terr. Phys., 42, 339, 1980.

Singer W., A. K. Knyazev, and J. Bremer, Empirical D-region electron density model for mid-latitudes, Paper presented at the COST 238 (PRIME) Workshop, E1 Arenosillo, Spain, 5-6 September, 1994.

Smirnova, N. V., O. F. Ogloblina, and V. A. Vlaskov, Models of the electron concentration in the ionospheric D region, Preprint PG1-84-08-36, Apatity, 1984.

Smirnova, N. V.,O. F. Ogloblina, and V. A. Vlaskov, Modeling of the lower ionosphere, PAGEOF, 127, 353, 1988. 